\section{Large Window Spectracon}

IN the Spectracon ${ }^{1}$ electronographic image tube, in the form now used for spectrographic recording, the image area is restricted to a rectangle $30 \mathrm{~mm} \times 5 \mathrm{~mm}$ to enable a very thin $(4 \mu \mathrm{m})$ mica Lenard window to be used which will support not only atmospheric pressure but also the pressure required to keep the electron-sensitive emulsion in intimate contact with the external mica surface when recording the image electrons.

Experience with this first type of tube has shown the high sensitivity of the device and high quality of the recorded images with excellent image definition, almost zero fog background, linear relationship of density with exposure and wide spectral range of sensitivity, thus making the tube very effective also for stellar photometry and the discrimination of faint objects against sky background. These possibilities were clearly shown by the work on stellar photometry by Walker ${ }^{2}$. This work also showed clearly the great advantage that would be gained if the effective window area could be substantially increased.

For some time Spectracons with mica windows $25 \mathrm{~mm} \times$ $10 \mathrm{~mm}$ have been made and used successfully ${ }^{3}$. As the tube has unity electron image magnification, the photocathode must be of the same dimensions as the window and hence a photocathode plate $10 \mathrm{~mm}$ wide must be transferred into the tube and the transfer tube sealed off under vacuum without damaging the photocathode.

To make a tube with a substantially larger mica window, say, $25 \mathrm{~mm} \times 20 \mathrm{~mm}$, required also a photocathode of the same dimensions. Trials with mica windows $25 \mathrm{~mm} \times 20 \mathrm{~mm}$ and $\approx 4 \mu \mathrm{m}$ thick showed that these were surprisingly reliable and stood up to combined atmospheric pressure and also the application of emulsion-coated film many hundred times without fracture.

Thus the strength of the mica window seemed adequate and the outstanding problem was to provide the photocathode of necessary area. To insert a photocathode plate of $20 \mathrm{~mm}$ width through a glass transfer tube and seal it off proved very difficult. Hence, as a compromise, photocathodes were prepared on two glass plates $30 \mathrm{~mm} \times 10 \mathrm{~mm}$ lying side-byside in an activation tube. In this way, there was practically no discontinuity in the photocathode sensitivity along the edges adjacent to one another. These two plates were then transferred to the Spectracon envelope with a $25 \mathrm{~mm} \times 20 \mathrm{~mm}$ mica window through a standard $11 \mathrm{~mm}$ transfer tube by the technique already described and mounted with the same sides in contact in the photocathode mounting frame. It was found to be very important to mount these plates with their photo-

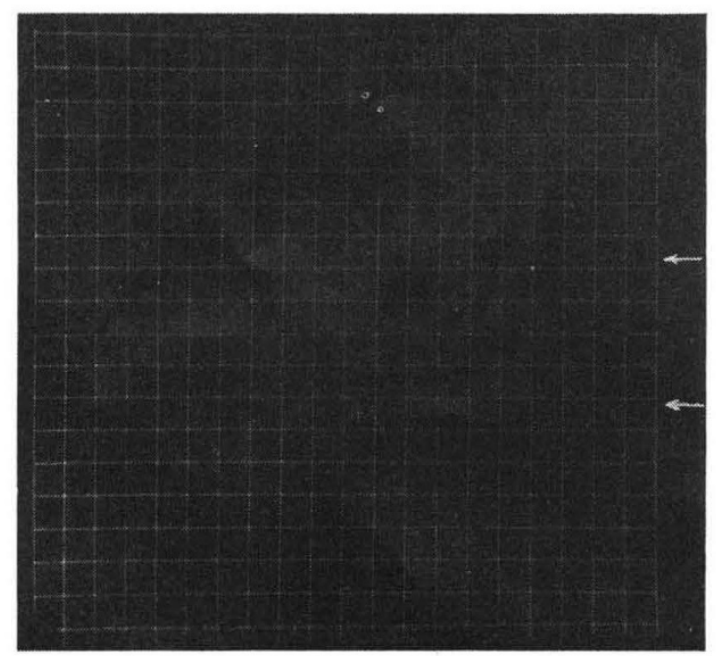

Fig. 1 Rectangular grid pattern $22 \mathrm{~mm} \times 20 \mathrm{~mm}$ recorded by Spectracon, Arrows indicate effective width of window of "standard" Spectracon.

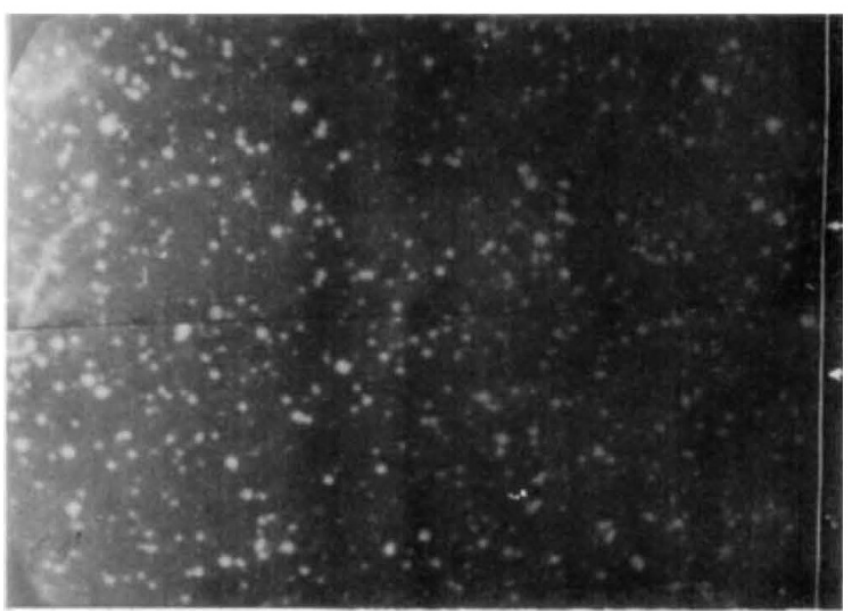

Fig. 2 Simulated star field picture reproduced by Spectracon (original size $25 \times 20 \mathrm{~mm}^{2}$ ).

cathode surfaces accurately coplanar, otherwise electron-image distortion was serious.

Only minor modifications to the tube, film applicator and focusing solenoid were necessary to make and operate this tube, and hence the device is convenient for use at the prime focus of a telescope. It has now been under test and in use for six months and has proved to be very reliable. The image quality over the effective image area of $25 \mathrm{~mm} \times 20 \mathrm{~mm}$ is substantially identical with that of the standard tube over its window area of $25 \mathrm{~mm} \times 5 \mathrm{~mm}$.

Fig. 1 shows a reproduction of a grid pattern used to test the geometrical accuracy of the electron image, and it can be seen that, for an image tube, this is exceptionally accurate. In Fig. 2 is reproduced a recording of a simulated star field, such as might be recorded at the prime focus of a telescope, and it shows that the image quality is comparable with that of a standard tube. The discontinuity across the picture where the two photocathode plates join is clearly visible but is considered to be a small penalty to pay for the increase by a factor of more than four in the effective image area. A process for eliminating this is now being investigated.

It is not practicable to show in a reproduced photograph experimental evidence of the limiting resolution of this tube, but careful tests show that it is $\geq 70 \mathrm{l} . \mathrm{p} / \mathrm{mm}$ over substantially the whole area shown in Figs. 1 and 2.

\section{J. D. MCGeE \\ C. I, Coleman \\ E. G. Phillips}

Physics Department,

Imperial College of Science and Technology, London SW7

Received October 30, 1972.

${ }^{1}$ McGee, J. D., McMullan, D., Bacik, H., and Oliver, M., Adv. Electronics Electron Phys., 28A, 61 (1969).

2 Walker, M. F., Sky and Telescope, 40, 132 (1970).

3 McGee, J. D., Bacik, H., Coleman, C. I., and Morgan, B. L., Adv. Electronics Electron Phys., 33A, 13 (1972).

\section{Allende Meteorite Carbonaceous Phase: Intractable Nature and Scanning Electron Morphology}

METEORITES, being solar nebula condensates ${ }^{1}$, should carry information on the processes which led to formation of the planets. Within this context Green, Radcliffe and Heuer ${ }^{2}$ studied $1 \mu \mathrm{m}$ thick foils of the Allende C-3 chondrite by means of high voltage transmission electron microscopy (TEM). Its chondrules (small silicate spheres) showed features which 